University of Nebraska - Lincoln

DigitalCommons@University of Nebraska - Lincoln

2010

\title{
The local structure of transition metal doped semiconducting boron carbides
}

Jing Liu

University of Nebraska-Lincoln

Guangfu Luo

University of Nebraska at Omaha

Wai-Ning Mei

University of Nebraska at Omaha, physmei@unomaha.edu

Orhan Kizilkaya

Louisiana State University at Baton Rouge, orhan@lsu.edu

Eric D. Shepherd

University of Nebraska-Lincoln

See next page for additional authors

Follow this and additional works at: https://digitalcommons.unl.edu/physicsdowben

Part of the Physics Commons

Liu, Jing; Luo, Guangfu; Mei, Wai-Ning; Kizilkaya, Orhan; Shepherd, Eric D.; Brand, Jennifer I.; and Dowben, Peter A., "The local structure of transition metal doped semiconducting boron carbides" (2010). Peter Dowben Publications. 246.

https://digitalcommons.unl.edu/physicsdowben/246

This Article is brought to you for free and open access by the Research Papers in Physics and Astronomy at DigitalCommons@University of Nebraska - Lincoln. It has been accepted for inclusion in Peter Dowben Publications by an authorized administrator of DigitalCommons@University of Nebraska - Lincoln. 


\section{Authors}

Jing Liu, Guangfu Luo, Wai-Ning Mei, Orhan Kizilkaya, Eric D. Shepherd, Jennifer I. Brand, and Peter A. Dowben 


\title{
The local structure of transition metal doped semiconducting boron carbides
}

\author{
Jing Liu ${ }^{1}$, Guangfu Luo ${ }^{2,3}$, Wai-Ning Mei $^{2}$, Orhan Kizilkaya ${ }^{4}$, \\ Eric D Shepherd ${ }^{5}$, J I Brand ${ }^{5}$ and P A Dowben ${ }^{1}$ \\ ${ }^{1}$ Department of Physics and Astronomy and the Nebraska Center for Materials and Nanoscience, Behlen \\ Laboratory of Physics, University of Nebraska-Lincoln, PO Box 880111, Lincoln, NE 68588-0111 USA \\ ${ }^{2}$ Department of Physics, University of Nebraska at Omaha, Omaha, NE 68182-0266, USA \\ ${ }^{3}$ State Key Laboratory for Mesoscopic Physics and Department of Physics, Peking University, Beijing \\ 100871, People's Republic of China \\ ${ }^{4}$ The J. Bennett Johnston Sr. Center for Advanced Microstructures and Devices, Louisiana State \\ University, 6980 Jefferson Hwy., Baton Rouge LA 70806, USA \\ ${ }^{5}$ College of Engineering, and the Nebraska Center for Materials and Nanoscience, N209 Walter Scott \\ Engineering Center, 17th and Vine Streets, University of Nebraska-Lincoln, Lincoln, \\ NE 68588-0511, USA
}

Received 15 October 2009, in final form 17 December 2009

Published 11 February 2010

Online at stacks.iop.org/JPhysD/43/085403

\begin{abstract}
Transition metal doped boron carbides produced by plasma enhanced chemical vapour deposition of orthocarborane (closo-1,2- $\mathrm{C}_{2} \mathrm{~B}_{10} \mathrm{H}_{12}$ ) and $3 \mathrm{~d}$ metal metallocenes were investigated by performing $\mathrm{K}$-edge extended $\mathrm{x}$-ray absorption fine structure and $\mathrm{x}$-ray absorption near edge structure measurements. The $3 \mathrm{~d}$ transition metal atom occupies one of the icosahedral boron or carbon atomic sites within the icosahedral cage. Good agreement was obtained between experiment and models for Mn, Fe and Co doping, based on the model structures of two adjoined vertex sharing carborane cages, each containing a transition metal. The local spin configurations of all the $3 \mathrm{~d}$ transition metal doped boron carbides, Ti through $\mathrm{Cu}$, are compared using cluster and/or icosahedral chain calculations, where the latter have periodic boundary conditions.
\end{abstract}

(Some figures in this article are in colour only in the electronic version)

\section{Introduction}

Although transition metal doping of $\beta$-rhombohedral boron has been heavily investigated [1-5], the doping of semiconducting boron carbides has been driven largely by device applications. The ability to generate semiconducting grades of boron carbide by plasma enhanced chemical vapour deposition (PECVD) of carboranes permits the development of corrosion resistant, high temperature devices with many applications including neutron detection [6-14]. This PECVD based semiconducting boron carbide has been used to fabricate heterojunction diodes with silicon [6-10,15,16], silicon carbide [17] and other semiconducting boron carbides (making these devices all boron carbide devices) $[11,13,14,18]$ and a boron carbide transistor [19]. Boron carbide homojunctions have been fabricated by PECVD of carboranes, with nickel doping [20,21], cobalt doping [22] and iron doping [23], as indicated in figure 1. Indeed, nickel doping of boron carbide has opened a route to the fabrication of the first boron carbide Esaki tunnel diode [20,21].

Successful n-type doping of $\beta$-rhombohedral boron has been accomplished with dopants such as iron [1-4], vanadium [4], chromium [4], nickel [4] and cobalt [4], while $\mathrm{Cu}$ is a p-type dopant [5]. For the related boron carbides, nickel [20,21, 24,25] and iron [23] are certainly n-type dopants while cobalt may or may not [22] be a p-type dopant of the boron carbides, depending upon device temperature. The common route for semiconducting doping is to include a metallocene, $M\left(\mathrm{C}_{5} \mathrm{H}_{5}\right)_{2}, M=\mathrm{V}, \mathrm{Cr}, \mathrm{Mn}, \mathrm{Fe}, \mathrm{Co}, \mathrm{Ni}$, simultaneously with the carborane source molecule, during PECVD [20-25]. This chemistry provides a significant range of possible $3 \mathrm{~d}$ transition metal dopants of boron carbide, but a unified picture of the possible differences (and similarities) in local structure and electronic structure adopted 

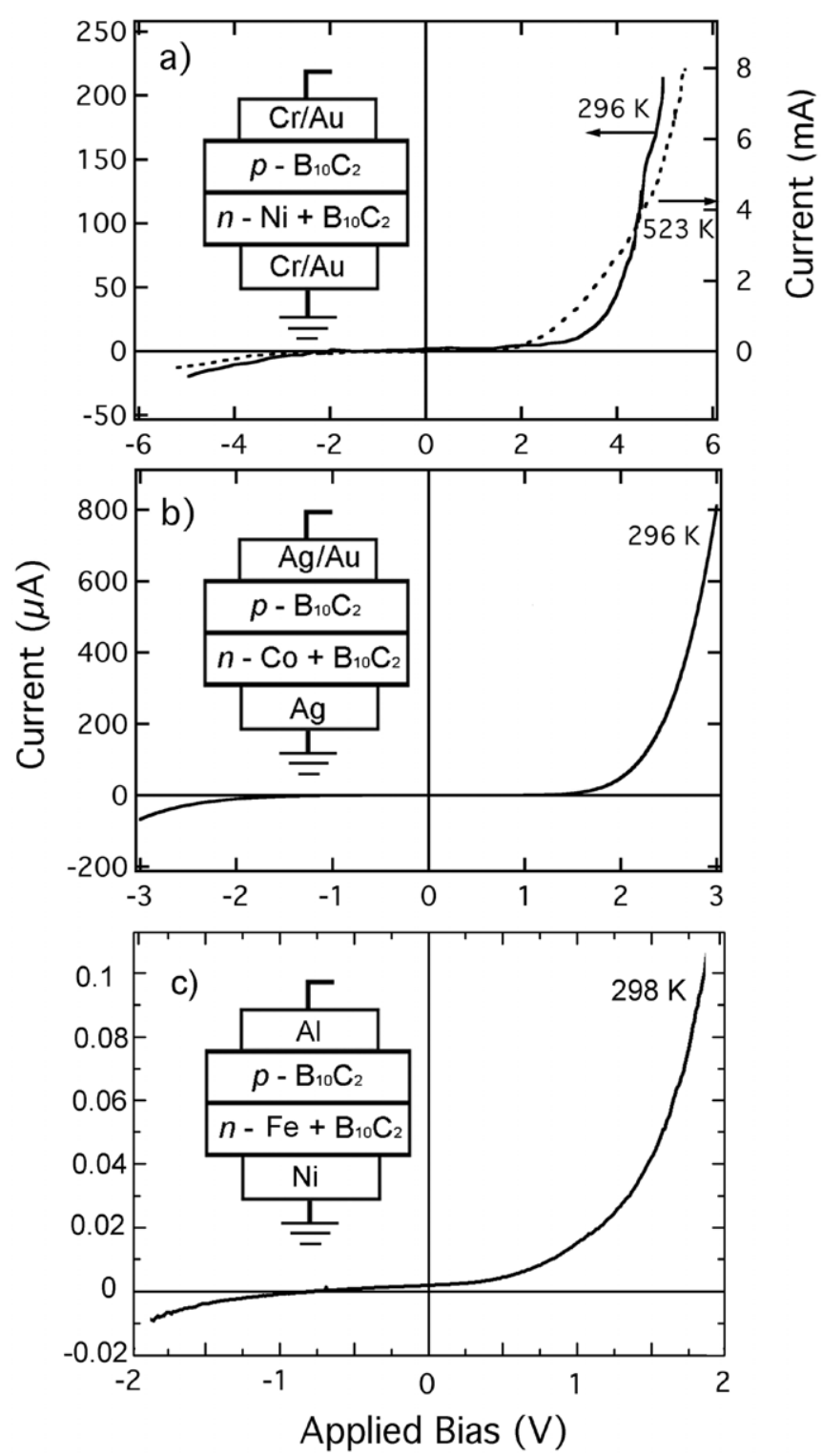

Figure 1. The $I-V$ characteristics of $(a) \mathrm{Ni}(\mathrm{n})-\mathrm{B}_{10} \mathrm{C}_{2} /$ (p)- $\mathrm{B}_{10} \mathrm{C}_{2}$ [20], (b) $\mathrm{Co}(\mathrm{n})-\mathrm{B}_{10} \mathrm{C}_{2} /(\mathrm{p})-\mathrm{B}_{10} \mathrm{C}_{2}$ [22] and (c) $\mathrm{Fe}(\mathrm{n})-\mathrm{B}_{10} \mathrm{C}_{2} /(\mathrm{p})-\mathrm{B}_{10} \mathrm{C}_{2}$ [23] diodes, formed by the PECVD decomposition of orthocarborane and the appropriate metallocene (see text). The insets are schematics of the various diodes, as assembled.

by each of these potential dopants in semiconducting boron carbide has not been developed. Successful n-type doping is well established as a practical matter. Thus, a variety of rectifying semiconducting boron carbide homojunction diodes can be readily fabricated, as demonstrated by figure 1 . The n-type doping of semiconducting boron carbides by transition metals at substitutional sites within the icosahedral cage is, nonetheless, difficult to understand without $3 \mathrm{~d}$ electron contributions to the valence band.

Given that these potential $3 \mathrm{~d}$ transition metal dopants of semiconducting boron carbide have a local magnetic moment, the local electronic structure in the vicinity of the dopant may also affect the local magnetic order, although this aspect remains as yet unexplored experimentally. This is an effort to bring a more unified picture to the local electronic structure of the doped semiconducting boron carbides fabricated by the PECVD of carboranes.

The historical challenge for modelling the electronic structure of the various semiconducting boron carbides has been that the structure has not been unequivocally elucidated, although some information about the local structure of the doped boron carbides has recently become available [22, 26]. The local structure of the cobalt doped semiconducting boron carbide has been determined by extended $\mathrm{x}$-ray absorption fine structure (EXAFS) and x-ray absorption near edge structure (XANES) spectroscopies [22,26] and to some extent in model cluster calculations [27]. Application of XANES and EXAFS techniques to determine the local structure of the undoped boron carbides has not been successful likely due to the low boron and carbon K-shell x-ray cross-sections [28, 29], although the extended electron energy loss fine structure has proved to be a comparatively useful technique [30]. With metal doping, at least local structure in the vicinity of the transition metal is now accessible. This opens a window to obtain the local structure of the semiconducting boron carbides using the 3d transition metal K-edge EXAFS spectroscopy.

\section{Experimental details}

The iron and manganese doped boron carbide films used for the XANES and EXAFS measurements were produced using PECVD with orthocarborane (closo-1,2dicarbadodecaborane; 1,2- $\mathrm{C}_{2} \mathrm{~B}_{10} \mathrm{H}_{12}$ ), ferrocene (for $\mathrm{Fe}$ ), manganocene (for $\mathrm{Mn}$ ) and argon as the plasma reactor gases, as previously described [20-26]. This PECVD approach is well established and has been successful in the fabrication of homojunction diodes [20-25] using 3d transition metal dopants to create an n-type material to the 'self-doped' slightly p-type undoped semiconducting boron carbide, as noted above and shown in figure 1 for some of the dopants studied here. Except for those fabricated with cobalt as the dopant, these homojunctions tend to preserve rectifying diode characteristics to temperatures well above room temperature.

Fe and Mn K-edge EXAFS spectra were collected at the DCM beamline at the Center for Advanced Microstructures and Devices (CAMD). Monochromatic light was obtained using a double crystal monochromator of the Lemonnier type [31], equipped with a $\operatorname{Ge}(220)$ crystal pair. The estimated energy resolution was approximately $2 \mathrm{eV}$. Spectra were collected in the fluorescence yield mode, using a silicon drift detector for the iron (Fe) doped boron carbide and using the Canberra 13-element high purity germanium diode array detector for manganese $(\mathrm{Mn})$ doped boron carbide. Due to the low transition metal concentrations, the data were not corrected for self-absorption. Two to five scans were collected to ensure reproducibility of the experimental data. The absolute energy scale was calibrated by assigning established K-edge to the first inflection point of the spectra taken from the appropriate metal foil. The EXAFS data were reduced according to the standard procedure [32], and analysed by the FEFF- 6 codes. The oscillatory photoabsorption cross section (for a K-shell 
excitation) is roughly:

$$
\begin{aligned}
\chi(k) & =k^{-1}|f(k, \theta)| \sum_{i} W_{i} \sin \left[2 k R_{i}+\alpha(k)\right] \\
& \times \exp \left(-\gamma R_{i}-2 \sigma_{i}^{2} k^{2}\right),
\end{aligned}
$$

where $f(k, \theta)$ is the atomic scattering factor and the weight from the atoms in each shell radius $i$, from the metal atom, is given in terms $W_{i}$. A typical experimental $\chi(k)$ spectrum weighted by $k$ demonstrates good data quality up to $\sim 11 \AA^{-1}$.

\section{The local structure in the vicinity of the transition metal dopant}

We have performed $\mathrm{Fe}$ and $\mathrm{Mn}$ K-edge XANES and EXAFS measurements of $\mathrm{Mn}$ and Fe doped PECVD grown semiconducting boron carbides ' $\mathrm{C}_{2} \mathrm{~B}_{10} \mathrm{H}_{x}$ '. The normalized Mn K-edge XANES spectrum of Mn-doped boron carbide, and the Fe K-edge XANES spectrum of Fe-doped boron carbide are shown in figure 2.

The characteristic signatures of manganese and iron are evident at values close to the expected [33] Mn K-edge $\left(E_{\mathrm{F}}-E_{\mathrm{K}}\right)$ at $6539 \mathrm{eV}$ (figure $\left.2(a)\right)$ and Fe K-edge $\left(E_{\mathrm{F}}-E_{\mathrm{K}}\right)$ at $7112 \mathrm{eV}$ (figure $2(b)$ ), respectively. We can infer from figure 2 that manganocene and ferrocene source gases do result in manganese and iron doping, respectively, of the PECVD grown boron carbides. This establishes that the sublimed molecular vapours of the various metallocenes $\left(M\left(\mathrm{C}_{5} \mathrm{H}_{5}\right)_{2}\right.$, $M=\mathrm{Fe}$ [23], Co [22,26] or Mn,), when added to the other PECVD source gases, appear to behave in a similar fashion in delivering the transition metal dopant during the plasma CVD process, although the similarities are in fact more significant as discussed below.

There are some distinctive features at the absorption edge of the Fe-doped boron carbide, indicating strong hybridization between iron and the inorganic host matrix. This is similar, in some respects, to that observed for the Co-doped PECVD grown ' $\mathrm{C}_{2} \mathrm{~B}_{10} \mathrm{H}_{x}$ ' semiconducting boron carbides, using cobaltocene [22-26]. The K-edge absorption is perhaps strongest for the Mn-doped boron carbide (as compared with the Fe [23] or Co [22,26] doped semiconducting PECVD boron carbide).

The Fourier transformed EXAFS wave vector weighted $k \chi(k)$ data, in radial coordinates, were obtained for Mn (solid lines in figure 3 ) and $\mathrm{Fe}$ (figure $4(b)$ ). The radial positions of peaks represent the distance between the absorbing $\mathrm{Mn}$ or $\mathrm{Fe}$ atom and their near neighbours within $6 \AA$. This makes possible acquisition of some structural and geometrical information of $\mathrm{Mn}$ or Fe doped boron carbides at a local level. The amplitude gives a qualitative description of the number of neighbours, and provides an overall sense of the local order. It is fairly clear from visual inspection of the magnitudes of the Fourier transformed EXAFS wave vector weighted $k \chi(k)$ data that the local order about the $\mathrm{Mn}$ (figure 3 ) or $\mathrm{Fe}$ (figure $4(b)$ ) transition metal atoms in semiconducting boron carbide is far greater than previously observed for cobalt doping of PECVD semiconducting boron carbide (figure 4(a)) [22,26]. In the case of the latter, the nearest neighbour and next nearest neighbour shells about the transition metal have strong

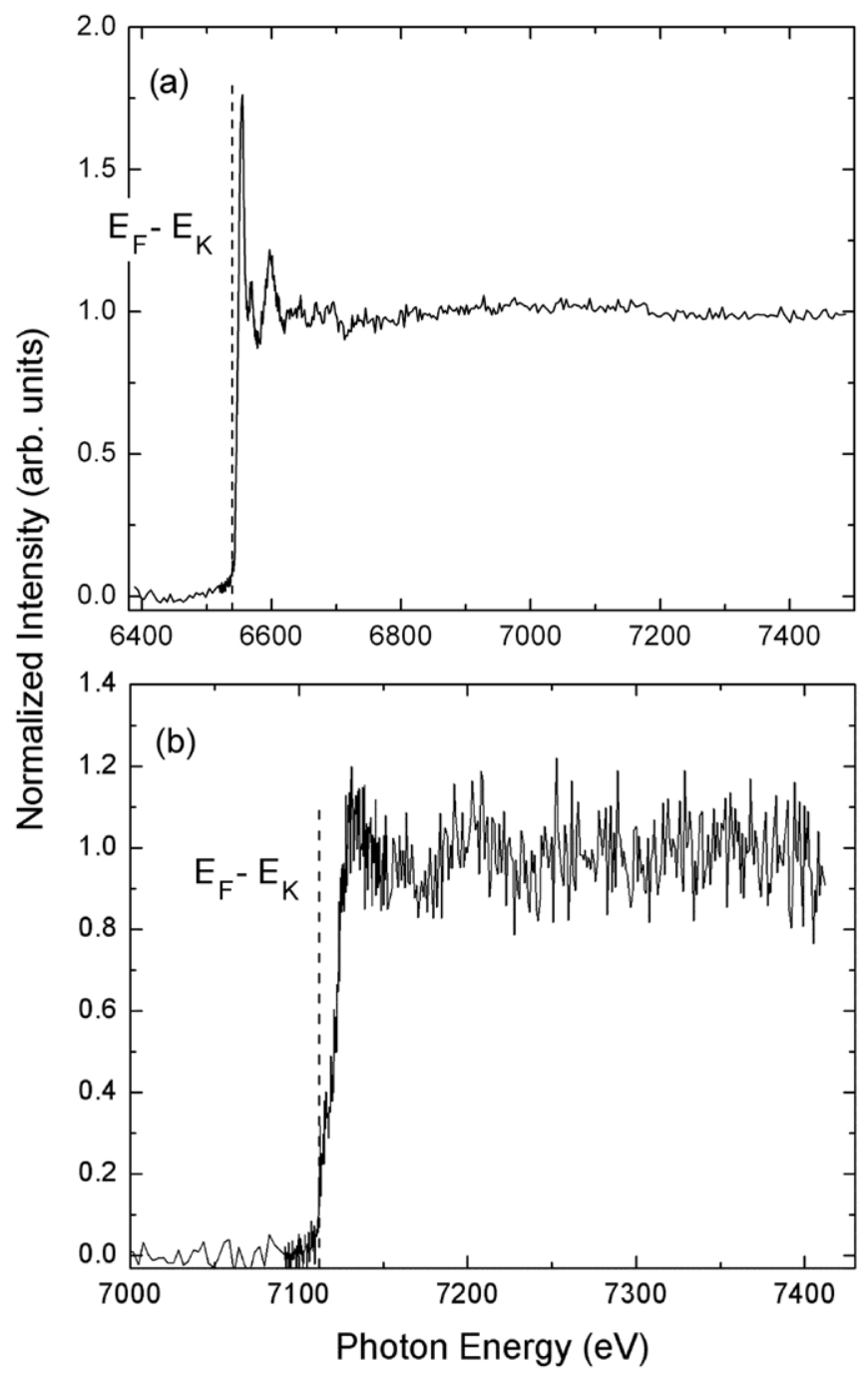

Figure 2. Normalized $\mathrm{Mn}(a)$ and $\mathrm{Fe}(b) \mathrm{K}$-edge XANES spectra of $\mathrm{Mn}$ and Fe doped PECVD semiconducting boron carbides, respectively. The Mn K-edge energy $\left(E_{\mathrm{F}}-E_{\mathrm{K}}\right)$ at $6539 \mathrm{eV}(a)$ and Fe K-edge energy $\left(E_{\mathrm{F}}-E_{\mathrm{K}}\right)$ at $7112 \mathrm{eV}(b)$ are highlighted, where $E_{\mathrm{K}}$ is the K-edge energy adapted from [33].

components, but weaken dramatically with increasing radius compared with $\mathrm{Fe}$, and particularly Mn-doped semiconducting boron carbides.

The major peak in the Fourier transformed EXAFS $k \chi(k)$ data at $1.4 \AA$ is due to single-scattering contribution of $\mathrm{Mn}-\mathrm{B}(\mathrm{C})$ (figure 3) or $\mathrm{Fe}-\mathrm{B}(\mathrm{C})$ (figure 4(b)) pairs, which can be considered as nearest neighbours with the pertinent transition metal dopant. Peaks observed between 1.96 and $4.5 \AA$ are due to $M-X$ pairs (where $M$ is $\mathrm{Mn}$ in figure 3 and $\mathrm{Fe}$ in figure 4(b), while $X$ could be either boron or carbon) and multiple scattering contributions, as occurs with increasing radius from the transition metal. The peak at $4 \AA$ in the Fourier transformed EXAFS $k \chi(k)$ data corresponds to other $\mathrm{Mn}-\mathrm{B}(\mathrm{C})$ (figure 3 ) or $\mathrm{Fe}-\mathrm{B}(\mathrm{C})$ (figure $4(b)$ ) pairs with longer distance from the $\mathrm{Mn}$ or $\mathrm{Fe}$ atom. The feature at about $5 \AA$ is associated with the $M-M$ pairs.

The structural parameters of $\mathrm{Mn}$ and Fe doped boron carbide were generated by both semi-empirical and ab initio calculations for all tested molecule models to simulate 


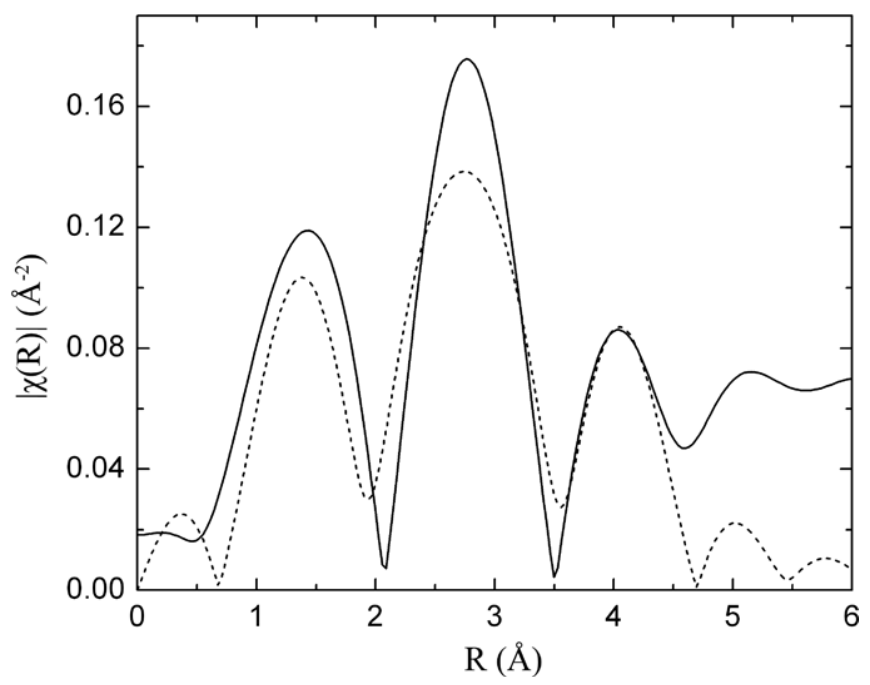

Figure 3. The Fourier transformed EXAFS $k \chi(k)$ data for the manganese doped PECVD semiconducting boron carbide are compared with the theoretical Fourier transformed EXAFS $k \chi(k)$ (broken line), using the schematic model of figure 5. The data are transformed for data taken between 4 and $8 \AA$.

EXAFS using the FEFF-6 codes. Geometry optimization was performed for a number of possible structural models by obtaining the lowest unrestricted Hartree-Fock energy states. Similar to the prior studies with cobalt doping of semiconducting boron carbides $[22,26]$, a number of local structural cluster models were tested for fit to the experimental EXAFS data.

Among the tested models, the best fit of the unfiltered EXAFS data is from the model of two adjoined icosahedral cages with $\mathrm{Mn}$ or $\mathrm{Fe}$ atom sitting in the apical icosahedral sites, possibly at a boron or carbon site for each cage, as schematically shown in figure 5 . The separation between two paired $\mathrm{Fe}$ ions is about $5.03 \pm 0.03 \AA$ while the $\mathrm{Mn}-\mathrm{Mn}$ separation was found to be close to $5.15 \pm 0.03 \AA$, all similar to the values found for $\mathrm{Co}-\mathrm{Co}$ pairs in cobalt doped boron carbide where the $M-M$ separation was found to be about $5.28 \pm 0.02 \AA$. We find that this model (figure 5), involving transition metal atom $M-M$ pairs sitting in the apical sites on opposite sides of the adjacent icosahedra, reasonably accounts for all major features shown in the EXAFS spectra for all three transition metal doped PECVD semiconducting boron carbides. The difference in magnitudes between the experimental and modelling curves mainly reflects low concentration of manganese or iron in the material. Other tested models, in which the metal atoms are not paired, do not show agreement with the experimental data, especially in the region corresponding to lattice constants greater than $3 \AA$. This effect was noted previously in the studies of cobalt doped boron carbides $[22,26]$. Compared with the case of cobalt doped boron carbides, the modelling of the EXAFS data favours the formation of metal-metal pairs to an even greater extent with Mn and Fe doping, but in all cases the peak locations for $\mathrm{Mn}-\mathrm{Mn}, \mathrm{Fe}-\mathrm{Fe}$ and $\mathrm{Co}-\mathrm{Co}$ pairs are all very close, at about $5 \AA$.

The distance for the single-scattering contributions from both the $\mathrm{Mn}-\mathrm{B}(\mathrm{C})$ nearest neighbour pairs and $\mathrm{Fe}-\mathrm{B}(\mathrm{C})$ pairs

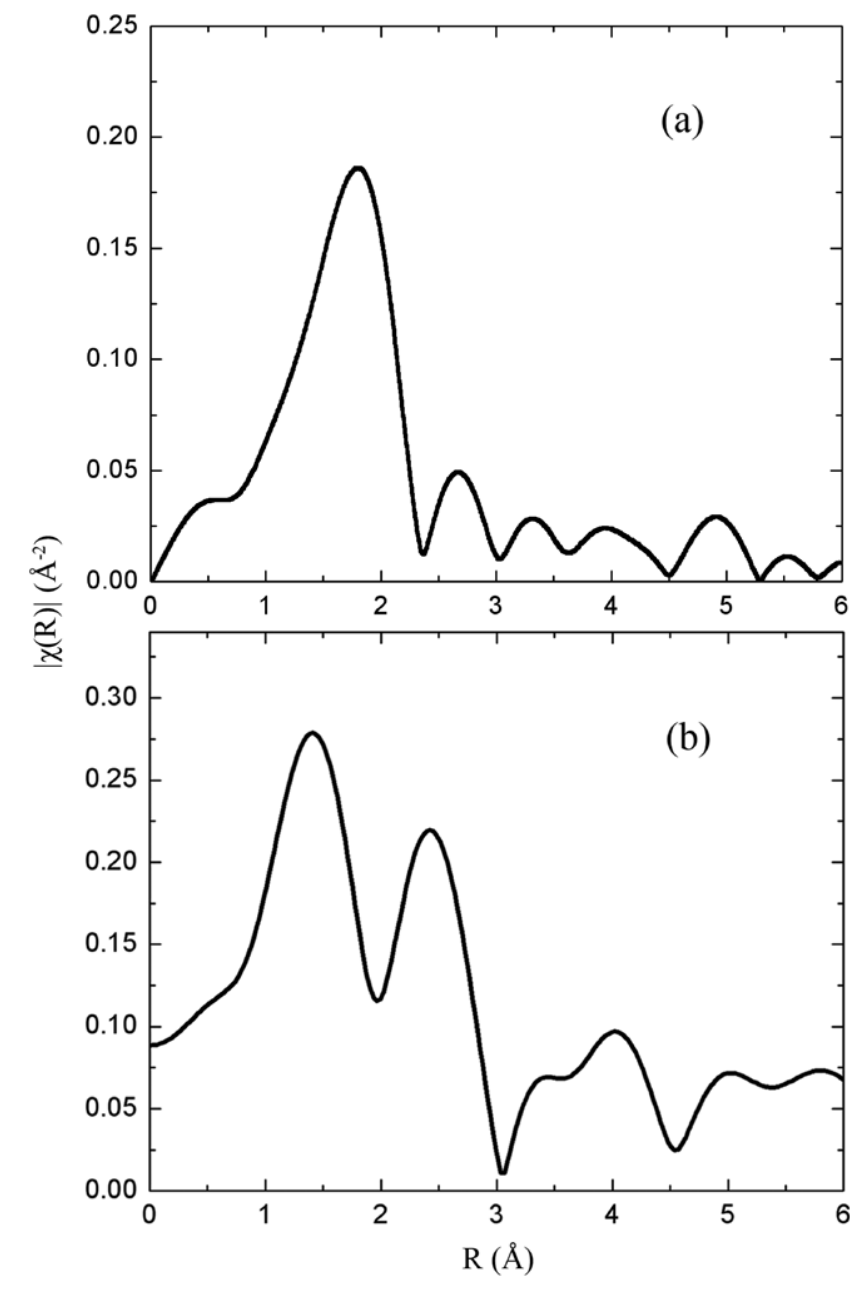

Figure 4. Magnitude of the Fourier transformed EXAFS $k \chi(k)$ data for $(b)$ the iron doped PECVD semiconducting boron carbides are compared with $(a)$ that of cobalt doped PECVD semiconducting boron carbide.

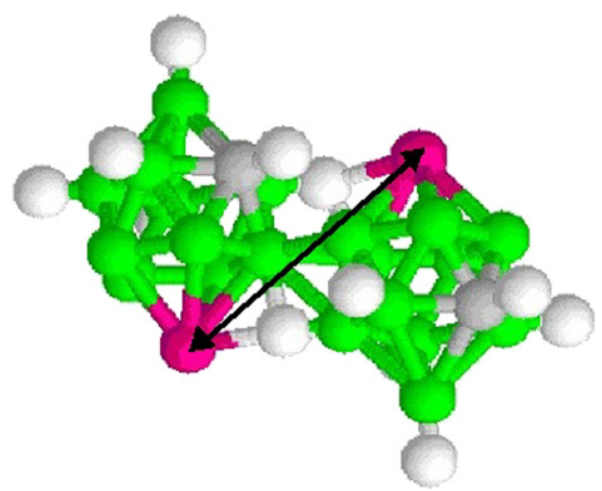

Figure 5. Schematic of the transition metal capped co-joined icosahedra structures with a metal to $\mathrm{C}$ distance of about $2 \AA$ to satisfy the EXAFS derived results. The transition metal atoms sit on opposite sides in the apical sites on the adjacent icosahedra, with a metal to metal distance (indicated by the arrow) chosen again to fit the EXAFS derived results.

is about $1.4 \AA$, smaller than for the cobalt case (1.8 $\AA$ ). This suggests that the manganese and iron atoms prefer to sit in the icosahedral apical sites in positions much closer to the boron and carbon atoms than is the case for cobalt. This tends to 

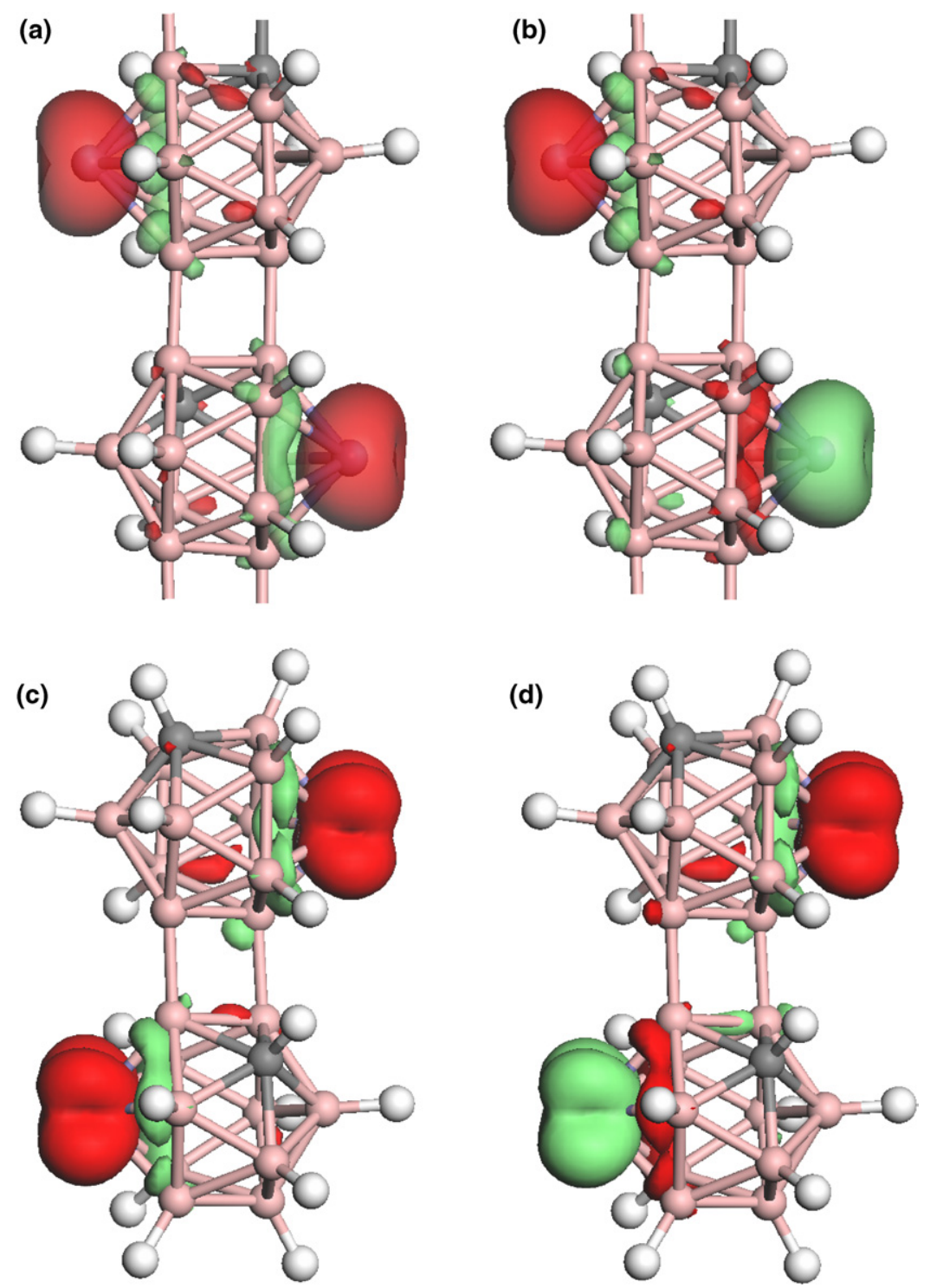

Figure 6. The spin distribution on the optimized structure, with an isovalue of 0.0179 a.u for the stable ferromagnetic high spin $(a)$, $(c)$ and less stable low spin $(b),(d)$ configurations of Fe pairs on opposite sides (UD) of the adjacent icosahedra for both the infinite chains structures with periodic boundary conditions, i.e. $\mathrm{Fe}_{2}-\mathrm{C}_{2} \mathrm{~B}_{20} \mathrm{H}_{14}$ (as shown in $(a)$ and $(b)$ ) and the clusters $\mathrm{Fe}_{2}-\mathrm{C}_{2} \mathrm{~B}_{20} \mathrm{H}_{18}$ (as shown in $(c)$ and $(d)$ ).

indicate the greater stability of the $\mathrm{Mn}$ and Fe doped boron carbide structures and stronger bonds formed between $\mathrm{B}(\mathrm{C})$ and either Mn or Fe atoms.

The $a b$ initio Co K-edge XANES [22,26] and $\mathrm{Co}, \mathrm{Fe}$ and Mn EXAFS spectra simulations suggest that all three transition metals adopt an endohedral position occupying apical sites within the icosahedral cage, as indicated in figures 5 and 6 , giving the transition atom a five-fold coordination to the nido-carborane $\mathrm{CB}_{11}$ cage. This is very much like a number of known metalloboranes [34]. In some of the known metalloborane examples, there is a conversion of adjacent icosahedra by removal of a $\mathrm{B}, \mathrm{BH}, \mathrm{C}$ or $\mathrm{CH}$ vertex, followed by introduction of the $\left(\mathrm{C}_{5} \mathrm{H}_{5}\right) \mathrm{M}$ vertex $[34,35]$. This should be a facile reaction [34]. Given the structural similarities among all three transition metal doped semiconducting PECVD boron carbides, we can make now some estimates of electronic structure, at least in the region of the transition metal dopant, from $a b$ initio theory. Two approaches are possible: cluster calculations using $M_{2}-\mathrm{C}_{2} \mathrm{~B}_{20} \mathrm{H}_{18}$ clusters $(M=\mathrm{Ti}, \mathrm{V}, \mathrm{Cr}$, $\mathrm{Mn}, \mathrm{Fe}, \mathrm{Co}, \mathrm{Ni}$ and $\mathrm{Cu}$ ), as were used to help solve and fit the EXAFS data, or chains of doped icosahedra with periodic boundary conditions.

\section{The local electronic structure and likely local spin configurations for the transition metal doped semiconducting boron carbides}

All the first-principles calculations are performed in the framework of density functional theory as implemented in the $\mathrm{DMol}^{3}$ code $[36,37]$. The PW91 generalized gradient approximation (GGA) was used for the exchange-correlation functional because of the better performance of GGA than the local density approximation (LDA) in many molecular systems. All the electrons were considered equally, and the double numerical plus polarization (DNP) basis set, which is comparable to the $6-31 G^{* *}$ basis set, was used. The 
Table 1. Total energy difference $(\mathrm{eV})$ between stable structures with metal pairs on the same $\left(E_{\mathrm{uu}}\right)$ and opposite sides $\left(E_{\mathrm{ud}}\right)$ of the adjacent icosahedra for both the infinite chain structures with periodic boundary conditions, i.e. $M_{2}-\mathrm{C}_{2} \mathrm{~B}_{20} \mathrm{H}_{14}(M=\mathrm{Ti}, \mathrm{V}, \mathrm{Mn}$ and $\mathrm{Fe})$ and the clusters $M_{2}-\mathrm{C}_{2} \mathrm{~B}_{20} \mathrm{H}_{18}(M=\mathrm{Ti}, \mathrm{V}, \mathrm{Cr}, \mathrm{Mn}, \mathrm{Fe}, \mathrm{Co}$, $\mathrm{Ni}$ and $\mathrm{Cu}$ ), as shown in figure 6 , with the latter values in brackets () . The total energy difference $(\mathrm{eV})$ between the high- and low-spin configurations and average magnetic moment magnitude $\left(\mu_{\mathrm{B}}\right)$ per atom with the metal pairs on the opposite sides of the adjacent icosahedra for both the $M_{2}-\mathrm{C}_{2} \mathrm{~B}_{20} \mathrm{H}_{14}(M=\mathrm{Ti}, \mathrm{V}, \mathrm{Mn}$ and $\mathrm{Fe})$ infinite chains and $M_{2}-\mathrm{C}_{2} \mathrm{~B}_{20} \mathrm{H}_{18}(M=\mathrm{Ti}, \mathrm{V}, \mathrm{Mn}, \mathrm{Fe} \mathrm{Cr}, \mathrm{Co}, \mathrm{Ni}$ and $\mathrm{Cu}$ ) molecular clusters have also been tabulated with the latter numbers again in brackets ().

\begin{tabular}{llll}
\hline Metal & $\begin{array}{l}E_{\mathrm{uu}}-E_{\mathrm{ud}} \\
(\mathrm{eV})\end{array}$ & $\begin{array}{l}E_{\text {high spin }}-E_{\text {low spin }} \\
(\mathrm{eV})\end{array}$ & $\begin{array}{l}\text { Average magnetic } \\
\text { momentum }\left(\mu_{\mathrm{B}}\right)\end{array}$ \\
\hline $\mathrm{Ti}$ & $0.46(0.32)$ & $-0.002(0.00)$ & $0.85(1.05)$ \\
$\mathrm{V}$ & $0.59(0.34)$ & $-0.02(-0.02)$ & $2.15(2.2)$ \\
$\mathrm{Mn}$ & $0.78(0.51)$ & $0.003(0.13)$ & $3.45(3.2)$ \\
$\mathrm{Fe}$ & $1.1(0.44)$ & $-0.24(-0.01)$ & $1.1(1.1)$ \\
$\mathrm{Cr}$ & $(0.36)$ & $(-0.03)$ & $(3.3)$ \\
$\mathrm{Co}$ & $(0.59)$ & Non-magnetic & Non-magnetic \\
& & spin configuration & spin configuration \\
$\mathrm{Ni}$ & $(0.51)$ & Non-magnetic & Non-magnetic \\
& & spin configuration & spin configuration \\
$\mathrm{Cu}$ & $(0.08)$ & Non-magnetic & Non-magnetic \\
& & spin configuration & spin configuration \\
\hline
\end{tabular}

convergence tolerance for the self-consistent field is $2.72 \times$ $10^{-6} \mathrm{eV}$, and the structures were optimized till the maximum force is below $0.054 \mathrm{eV}^{-1}$. To explore the possible magnetic ordering configurations, different initial spin states of the transition metal atoms in the spin-polarized calculated model systems were considered and optimized. Where possible, the electronic structure and spin configuration for metal atom pairs on the same (UU) and opposite sides (UD) of the adjacent icosahedra for both the infinite chain structures with periodic boundary conditions, i.e. $M_{2}-\mathrm{C}_{2} \mathrm{~B}_{20} \mathrm{H}_{14}(M=\mathrm{Ti}, \mathrm{V}$, $\mathrm{Mn}$ and $\mathrm{Fe})$ and the clusters $M_{2}-\mathrm{C}_{2} \mathrm{~B}_{20} \mathrm{H}_{18}(M=\mathrm{Ti}, \mathrm{V}, \mathrm{Cr}, \mathrm{Mn}$, $\mathrm{Fe}, \mathrm{Co}, \mathrm{Ni}$ and $\mathrm{Cu}$ ) were calculated. These are schematically shown in figure 6 .

We find that energetically the transition metal atoms prefer to situate at the alternate sides of the chain or symmetric axis when in molecular clusters, as summarized in table 1. This is in good agreement with our experimentally derived local structure (figure 5). The differences in energy between the unfavourable structure placing the transition metals on the same side (UU) and favourable structures placing the transition metals on opposite sides (UD) of the adjacent icosahedra vary from 0.3 to $0.5 \mathrm{eV}$ regardless of spin configurations.

From spin-polarized calculations, we find that $\mathrm{Ti}, \mathrm{V}, \mathrm{Cr}$ and $\mathrm{Fe}$ favour the high-spin stable ground states, i.e. the spins are roughly aligned in the same direction and the net spin magnetic moments on the transition metal atoms are non-zero. Manganese prefers a low-spin configuration. For $\mathrm{Co}, \mathrm{Ni}$ and $\mathrm{Cu}$, non-magnetic states are adopted where not only are the net magnetic moments zero, but also the systems are entirely nonmagnetic with no local magnetic order at all. We attributed this situation observed for $\mathrm{Co}, \mathrm{Ni}$ and $\mathrm{Cu}$ to the hybridization between the more than half-filled $d$ shell and s levels. Such hybridization effects have been suggested to result in reduced magnetic moments in Co and Ni clusters [38] and thus are not entirely unexpected.

The atomic charges of all the carborane cluster and carborane chain systems, with $3 \mathrm{~d}$ transition metal substitutions, were analysed by using the Hirshfeld method (as implemented in DMol3), which has been shown to give chemically meaningful results [39]. The detailed average electron charges for the metal pairs on opposite sides of the adjacent icosahedra for both the clusters $M_{2}-\mathrm{C}_{2} \mathrm{~B}_{20} \mathrm{H}_{18}(M=$ $\mathrm{Ti}, \mathrm{V}, \mathrm{Cr}, \mathrm{Mn}, \mathrm{Fe}, \mathrm{Co}, \mathrm{Ni}$ and $\mathrm{Cu}$ ) and infinite chain structures with periodic boundary conditions, i.e. $M_{2}-\mathrm{C}_{2} \mathrm{~B}_{20} \mathrm{H}_{14}(M=$ $\mathrm{Ti}, \mathrm{V}, \mathrm{Cr}, \mathrm{Mn}, \mathrm{Fe}, \mathrm{Co}, \mathrm{Ni}$ and $\mathrm{Cu}$ ) are summarized in table 2. The calculated average atomic charges differ little between the high- and low-spin configurations as calculated by the Hirshfeld method [39]. For comparison, the results by using the Mulliken method are also listed. Generally, the average charge state on each transition metal is in the range of 0.3-0.6 $|\mathrm{e}|$, which suggests that the transition metal generally adopts a covalently bonded like scenario.

The bond lengths of the five $M-\mathrm{B}$ bonds are different for different spin configurations. There are small differences $\delta L$ in the $M-\mathrm{B}$ bond lengths between the high- and low-spin configurations for $\mathrm{Ti}, \mathrm{V}, \mathrm{Cr}, \mathrm{Mn}$ and $\mathrm{Fe}$, as listed in table 3. While these bond length differences $\delta L$ are small for some transition metal systems, there are differences nonetheless. We find a strong connection between the stable structures and the bond lengths that do depend upon the local spin configuration for Mn-doped clusters and chains. The bond length differences between the transition metal atoms and nearby boron atoms in the high- and low-spin ground states are very similar for all cases, with the maximum $\delta L$ ranging at most from 0.004 to $0.009 \AA$, for $\mathrm{Ti}, \mathrm{V}, \mathrm{Cr}$ and $\mathrm{Fe}$. However, in the case of $\mathrm{Mn}, \delta L$ is as large as $0.123 \AA$. In the non-magnetic systems containing $\mathrm{Co}, \mathrm{Ni}$ and $\mathrm{Cu}$, only an average bond length can be cited. Accordingly, we may expect slightly different fits to the experimental structural data from EXAFS for Ti, V, Cr, Mn and Fe doped PECVD semiconducting boron carbides, depending on the model spin configuration used, as indicated in figure 7.

Of course, for the PECVD grown semiconducting boron carbides, the transition metal atoms are very likely to be more highly coordinated than in the models of figure 6 . We can expect that the greater coordination that is likely to occur in the semiconducting solid material will also result in changes to bond length as well as diminish any differences in the bond lengths between the high-spin and low-spin configurations. Generally, the $M-\mathrm{B}(\mathrm{C})$ bond lengths obtained from theory are in the region of $2 \AA$, as expected from the analysis of the EXAFS experiments, although somewhat larger as summarized in table 3. Again, this is expected for a metal atom that might not be as fully coordinated as may occur in the solid boron carbide semiconductor.

\section{Conclusion}

From the analysis of Mn and Fe K-edge XANES and EXAFS spectra, there are indications that the manganese and iron atoms are chemically bonded within icosahedral boron carbide cages of PECVD grown semiconducting boron carbides, in a 
Table 2. The average atomic charges for the metal pairs on opposite sides of the adjacent icosahedra for both the clusters $M_{2}-\mathrm{C}_{2} \mathrm{~B}_{20} \mathrm{H}_{18}$ $(M=\mathrm{Ti}, \mathrm{V}, \mathrm{Cr}, \mathrm{Mn}, \mathrm{Fe}, \mathrm{Co}, \mathrm{Ni}$ and $\mathrm{Cu})$ and infinite chain structures with periodic boundary conditions, i.e. $M_{2}-\mathrm{C}_{2} \mathrm{~B}_{20} \mathrm{H}_{14}(M=\mathrm{Ti}, \mathrm{V}, \mathrm{Cr}$, $\mathrm{Mn}, \mathrm{Fe}, \mathrm{Co}, \mathrm{Ni}$ and $\mathrm{Cu}$ ), as shown in figure 6. The average atomic charges calculated differ little between the high- and low-spin configurations as calculated by the Hirshfeld method [39] and again by the Mulliken method, shown in brackets ().

\begin{tabular}{llllll}
\hline & \multicolumn{2}{c}{ Cluster } & & \multicolumn{2}{c}{ Chain } \\
\cline { 2 - 3 } \cline { 5 - 6 } $\begin{array}{l}\text { Transition } \\
\text { Metal }\end{array}$ & $\begin{array}{l}\text { Atomic charge } \\
(|\mathrm{e}|) \text { of the } \\
\text { high-spin state }\end{array}$ & $\begin{array}{l}\text { Atomic charge } \\
(|\mathrm{e}|) \text { of the } \\
\text { low-spin state }\end{array}$ & & $\begin{array}{l}\text { Atomic charge } \\
(|\mathrm{e}|) \text { of the } \\
\text { high-spin state }\end{array}$ & $\begin{array}{l}\text { Atomic charge } \\
(|\mathrm{e}|) \text { of the } \\
\text { low-spin state }\end{array}$ \\
\hline $\mathrm{Ti}$ & $0.652(0.534)$ & $0.652(0.534)$ & & $0.617(0.454)$ & $0.617(0.454)$ \\
$\mathrm{V}$ & $0.559(0.408)$ & $0.561(0.409)$ & & $0.541(0.364)$ & $0.541(0.365)$ \\
$\mathrm{Cr}$ & $0.659(0.266)$ & $0.659(0.267)$ & & $0.643(0.219)$ & $0.644(0.220)$ \\
$\mathrm{Mn}$ & $0.445(0.241)$ & $0.480(0.271)$ & & $0.444(0.251)$ & $0.442(0.243)$ \\
$\mathrm{Fe}$ & $0.388(0.297)$ & $0.389(0.298)$ & & $0.379(0.273)$ & $0.386(0.285)$ \\
$\mathrm{Co}$ & $0.331(0.077)$ & & $0.318(0.033)$ \\
$\mathrm{Ni}$ & $0.291(0.248)$ & & $0.281(0.220)$ \\
$\mathrm{Cu}$ & $0.483(0.109)$ & & $0.459(0.018)$ \\
\hline
\end{tabular}

Table 3. The $M-\mathrm{B}$ bond and maximum length difference, $\delta \mathrm{L}$, between the high- and low-spin states of $M_{2}-\mathrm{C}_{2} \mathrm{~B}_{20} \mathrm{H}_{18}$.

\begin{tabular}{lllc}
\hline$M$ & High spin & Low spin & $\delta \mathrm{L}(\AA)$ \\
\hline $\mathrm{Ti}$ & 2.184 & 2.181 & 0.003 \\
$\mathrm{~V}$ & 2.152 & 2.156 & -0.004 \\
$\mathrm{Cr}$ & 2.157 & 2.162 & -0.005 \\
$\mathrm{Mn}$ & 2.087 & 2.210 & -0.123 \\
$\mathrm{Fe}$ & 2.009 & 2.017 & -0.008 \\
$\mathrm{Co}$ & 2.020 & 2.020 & 0 \\
$\mathrm{Ni}$ & 2.058 & 2.058 & 0 \\
$\mathrm{Cu}$ & 2.236 & 2.236 & 0 \\
\hline
\end{tabular}

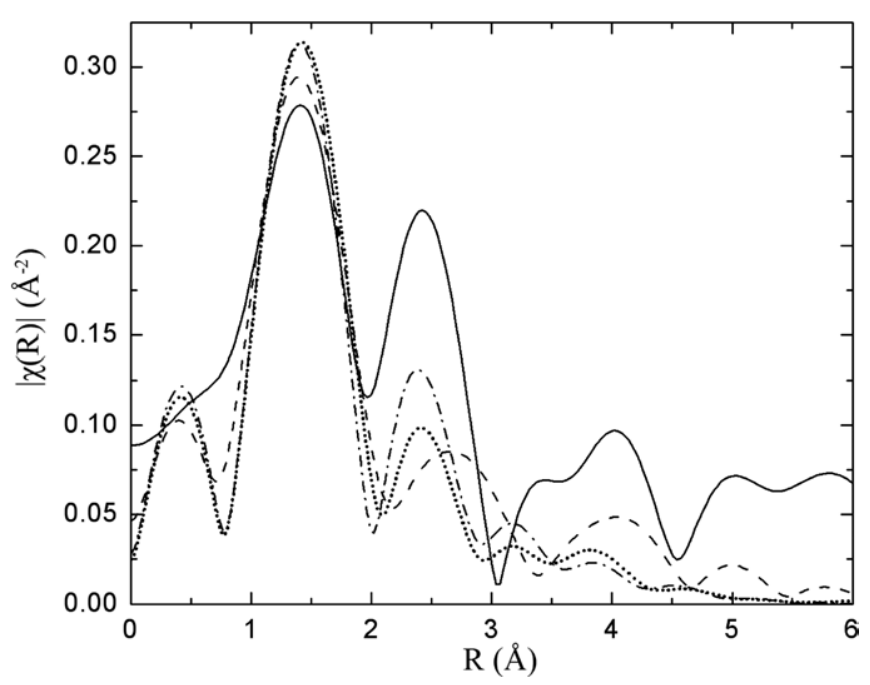

Figure 7. Comparison of the theoretical modelling of the Fourier transformed EXAFS of the iron doped PECVD semiconducting boron carbide. The magnitude of the Fourier transformed experimental EXAFS is shown as a solid line. The fitting curves are based on structural parameters calculated by semi-empirical calculation (dashed line) and density functional theory calculations with both the high-spin (dotted line) and low-spin (dash dot line) configurations, see text.

similar fashion to that observed for cobalt doping of PECVD grown semiconducting boron carbides. In all three transition metal examples for the doping of semiconducting boron carbides, the doping occurs pairwise with each transition metal sitting on adjacent adjoined icosahedral cages with a metal to metal spacing of about $5 \AA$. This observation is consistent with theory, while the adoption of an apical endohedral position within the cage, by the various transition metals, is consistent with known main group metalloborane synthetic chemistry $[34,35]$.

The spin density calculations indicate that $\mathrm{Ti}, \mathrm{V}, \mathrm{Cr}$ and $\mathrm{Fe}$ favour the high-spin stable ground states, while $\mathrm{Mn}$ prefers a low-spin antiferromagnetic configuration, and $\mathrm{Co}, \mathrm{Ni}$ and $\mathrm{Cu}$ adopt local non-magnetic spin configurations.

\section{Acknowledgments}

This work was supported by the Defense Threat Reduction Agency (Grant No. HDTRA1-09-1-0060), and the National Science Foundation (through grant ECS 0725881 and Materials Research Science and Engineering Center at the University of Nebraska-Lincoln, MRSEC grant DMR0820521), and the Chief Technical Officer, Intelligence Technology Innovation Center of the United States Intelligence Community. Guangfu Luo is a pre-PhD graduate student of the Department of Physics, Peking University, supported by the Chinese Scholarship council for the work at the University of Nebraska at Omaha. The authors acknowledge helpful conversation with Neil Boag.

\section{References}

[1] Takizawa H, Haze N, Okamoto K, Uheda K and Endo T 2002 Mater. Res. Bull. 37 113-21

[2] Kuhlmann U, Werheit H, Pelloth J, Keune W and Lundstrom T 1995 Phys. Status Solidi b 187 43-59

[3] Kuhlmann U, Werheit H, Dose T and Lundstrom T $1992 \mathrm{~J}$. Alloys Compounds 186 187-200

[4] Werheit H, Schmechel R, Kueffel V and Lundstrom T 1997 J. Alloys Compounds 262 372-80

[5] Matsuda H, Nakayama T, Kimura K, Murakami Y, Suematsu H, Koboyashi M and Higashi I 1995 Phys. Rev. B 526102

[6] Robertson B W, Adenwalla S, Harken A, Welsch P, Brand J I, Dowben P A and Claassen J P 2002 Appl. Phys. Lett. $803644-6$ 
[7] Robertson B W, Adenwalla S, Harken A, Welsch P, Brand J I, Claassen J P, Boag N M and Dowben P A 2002 Advances in Neutron Scattering Instrumentation ed I S Anderson and B Guérard Proc. SPIE 4785 226-33

[8] Adenwalla S, Billa R, Brand J I, Day E, Diaz M J, Harken A, McMullen-Gunn A, Padmanabhan R and Robertson B W 2003 Penetrating Radiation Systems and Applications $V$ Proc. SPIE 5199 70-4

[9] Lundstedt C, Harken A, Day E, Robertson B W and Adenwalla S 2006 Nucl. Instrum. Methods Phys. Res. A $562380-8$

[10] Harken A D, Day E E, Robertson B W and Adenwalla S 2005 Japan. J. Appl. Phys. 44 444-5

[11] Caruso A N, Billa R B, Balaz S, Brand J I and Dowben P A 2004 J. Phys.: Condens. Matter 16 L139-46

[12] Day E, Diaz M J and Adenwalla S 2006 J. Phys. D: Appl. Phys. 39 2920-4

[13] Caruso A N et al 2006 Mater. Sci. Eng. B 135 129-33

[14] Osberg K, Schemm N, Balkir S, Brand J I, Hallbeck S, Dowben P and Hoffman M W 2006 IEEE Sensors J. 6 1531-8

[15] Lee S, Mazurowski J, Ramseyer G and Dowben P A 1992 J. Appl. Phys. 72 4925-33

[16] Lee S and Dowben P A 1994 Appl. Phys. A 58 223-7

[17] Adenwalla S, Welsch P, Harken A, Brand J I, Sezer A and Robertson B W 2001 Appl. Phys. Lett. 79 4357-9

[18] Balaz S, Dimov D I, Boag N M, Nelson K, Montag B, Brand J I and Dowben P A 2006 Appl. Phys. A 84 149-59

[19] Hwang S-D, Byun D, Ianno N J, Dowben P A and Kim H R 1996 Appl. Phys. Lett. 68 1495-7

[20] Hwang S-D, Yang K, Dowben P A, Ahmad A A, Ianno N J, Li J Z, Lin J Y, Jiang H X and McIlroy D N 1997 Appl. Phys. Lett. 70 1028-30
[21] Hwang S-D, Remmes N, Dowben P A and McIlroy D N 1997 J. Vac. Sci. Technol. A 15 854-9

[22] Carlson L, La Graffe D, Balaz S, Ignatov A, Losovyj Ya B, Choi J, Dowben P A and Brand J I 2007 Appl. Phys. A 89195

[23] Dowben P A, Kizilkaya O, Liu J, Montag B, Nelson K, Sabirianov I and Brand J I 2009 Mater. Lett. 63 72-4

[24] McIlroy D N, Hwang S-D, Yang K, Remmes N, Dowben P A, Ahmad A A, Ianno N J, Li J Z, Lin J Y and Jiang H X 1998 Appl. Phys. A 67 335-42

[25] Hwang S-D, Remmes N B, Dowben P A and McIlroy D N 1996 J. Vac. Sci. Technol. B 14 2957-60

[26] Ignatov A Yu, Losovyj Ya B, Carlson L, La Graffe D, Brand J I and Dowben P A 2007 J. Appl. Phys. 102083520

[27] Dowben P A, Ignatov A Yu, Liu J and Skomski R $2008 \mathrm{~J}$. Appl. Phys. 103 07D125

[28] Lee S W et al 1993 J. Appl. Phys. 74 6919-24

[29] Jiménez I, Sutherland D G J, van Buuren T, Carlisle J A, Terminello L J and Himpsel F J 1998 Phys. Rev. B 5713167

[30] Lee S, Dowben P A, Wen A T, Hitchcock A P, Glass J A Jr and Spencer J T 1992 J. Vac. Sci. Technol. A 10 881-5

[31] Lemonnier M, Collet O, Depautex C, Esteva J M and Raoux D 1978 Nucl. Instrum. Methods A 152109

[32] Hayes T M and Boyce J B 1982 Solid State Physics ed H Ehrenreich et al (New York: Academic) vol 37 p 173

[33] Bearden J A and Burr A F 1967 Rev. Mod. Phys. 39125

[34] Hawthorne M F 1968 Acc. Chemical Res. 1281

[35] King R B 2001 Chem. Rev. 1011119

[36] Delley B 1990 J. Chem. Phys. 92508

[37] Delley B 2000 J. Chem. Phys. 1137756

[38] Liu S-R, Zhai H-J and Wang L-S 2002 Phys. Rev. B 65113401

[39] Guerra C F, Handgraaf J-W, Baerends E J and Bickelhaupt F M 2004 J. Comput. Chem. 25189 